\title{
Propaganda, promoção de vendas e atitude: um estudo quantitativo sobre suas relações
}

\section{Advertising, Sales Promotion and Attitude: a Quantitative Study on their Relationships}

\author{
FERNANDO HENRIQUE OLIVEIRA DE AGUIAR* \\ ALCIDES BARRICHELLO** \\ ROGÉRIO SCABIM MORANO*** \\ CAIO CÉSAR BIASE SPERANDIO**** \\ JÉSSICA PARENTE PARRA DE RIO*****
}

TARCILLA MAIANI DE ALMEIDA SOUZA HEYING*****

THALES ZOMINHAN Z $^{* * * * * *}$

\section{RESUMO}

Atualmente a propaganda e a promoção de vendas têm assumindo um papel significativo nas empresas para a sustentação dos patamares de negócios desejados. Infelizmente, dependendo de como são feitas, elas podem originar um efeito ricochete pela criação ou incremento do ceticismo dos consumidores fazendo com que eles se afastem. O objetivo do presente trabalho foi avaliar a relação entre ceticismo à propaganda, ceticismo às promoções de vendas e atitude em relação ao produto no segmento de telefonia celular. Adicionalmente foi pesquisada a ação

* Doutor em Administração pelo Centro Universitário FEI. fhoaguiar@yahoo.com.br .

** Universidade Presbiteriana Mackenzie. Professor de pós-graduação lato sensu do Centro de Ciências Sociais e Aplicadas da Universidade Presbiteriana Mackenzie.

alcidesbarrichel@uol.com.br .

*** Universidade Federal de São Paulo (UNIFESP). Prof. Dr. do Depto. de Ciências Exatas e da Terra Setor de Engenharia - Área de Gestão Industrial. Universidade Federal de São Paulo - UNIFESP. r.morano@uol.com.br .

**** Engenheiro de Produção pela Pontifícia Universidade Católica de São Paulo. caiosperandio@gmail.com .

***** Engenheira de Produção pela Pontifícia Universidade Católica de São Paulo. jessica_pprio@hotmail.com .

***** Engenheira de Produção pela Pontifícia Universidade Católica de São Paulo. tarcillaheying@hotmail.com .

******* Engenheiro de Produção pela Pontifícia Universidade Católica de São Paulo. thales_zominhan@hotmail.com . 
moderadora de algumas variáveis sobre essas relações, variáveis essas não comumente pesquisadas. Para lograr tal intento foram adaptados questionários existentes na literatura e aplicados a estudantes de graduação de universidades no estado de São Paulo. As análises foram feitas com o uso de modelagem de equações estruturais. Os resultados obtidos indicaram efeito negativo e significante do ceticismo à propaganda sobre atitude em relação ao produto e efeito positivo e significante do ceticismo à propaganda sobre ceticismo às promoções de vendas. Sexo, idade e origem dos respondentes não apresentaram diferenças quando da análise multigrupo realizada. Já o ano cursado, o tipo de escola, a área de formação e o tempo de troca dos aparelhos mostraram efeito moderador sobre as relações estudadas.

Palavras-chave: Ceticismo à propaganda; Ceticismo à promoção de venda; Atitude em relação a produtos; Modelagem de equações estruturais.

\section{Abstract}

Advertising and sales promotion are now playing a significant role in companies to support desired business levels. Unfortunately, depending on how they are made, they can generate a rebound effect by creating or increasing consumer skepticism. The objective of this study was to evaluate the relationship between skepticism to advertising, skepticism to sales promotion and attitude towards the product in the cellular segment. Additionally, the moderating action of some variables on these relationships, variables not commonly searched, was investigated. To achieve such intent, existing questionnaires in the literature were adapted and applied to undergraduate students from universities in the state of São Paulo. Analyzes were performed using structural equation modeling. Results indicated a negative and significant effect of skepticism to advertising onto attitude towards the product and positive and significant effect of skepticism to advertising onto skepticism to sales promotion. Sex, age and origin of the respondents did not present differences when multigroup analysis were performed. On the other hand, year attended, type of school, graduation area and time for device exchange showed a moderating effect on the relationships studied.

Keywords: Skepticism to advertising; Skepticism to sales promotion; Attitude towards the product; Structural equation modeling 


\section{INTRODUÇÃo}

O sistema de celular tem crescido exponencialmente desde que a tecnologia foi introduzida no Brasil há 25 anos. Dados da ANATEL indicam que o Brasil terminou outubro de 2017 com 240,9 milhões de celulares e densidade de 115,76 cel./100 hab. (ANATEL, 2017).

Ao longo das duas últimas décadas, inicialmente nos Estados Unidos e Japão, o mundo globalizado testemunhou o surgimento de um fenômeno que permeia a cultura contemporânea de forma inexorável: a propagação do uso de telefones celulares, que passaram a representar parte importante do cotidiano de um número cada vez maior de indivíduos, em diversos tipos de atividades. $\mathrm{O}$ telefone celular se estabeleceu como um dos utensílios símbolo da atualidade no contexto da sociedade de consumo multinacionalizada (SILVA, 2007). Ele se transformou em objeto equivalente a óculos ou relógios, representando a identidade do usuário já que seu uso envolve significados e experiências pessoais (DUTRA, 2016).

Por sua vez, a propaganda pode ser definida como um tipo de comunicação, integrada à comunicação social, com o objetivo de proporcionar uma boa imagem do produto anunciado, serviços, pessoas e empresas, de modo a estimular o consumo (PERRUPATO, 2006). Publicidade, em sua raiz, significa, genericamente, divulgar, tornar público um fato ou uma ideia (do latim "publicus", em português, "público"). Na sua origem, a palavra propaganda estava ligada à ideia de reprodução (do latim "propagare"), tendo sido usada pela Igreja Católica com a intenção de propagar a fé católica, assim como para a propagação de princípios, ideias, conhecimentos e teorias. Atualmente ela é considerada pelos estudiosos de Marketing como uma forma paga de apresentação ou promoção de ideias, bens ou serviços por parte de um patrocinador conhecido com o objetivo de divulgar informações para um público-alvo visando cativar seu interesse e consequente desejo de consumo. Nas atividades de marketing dificilmente existem negócios que não façam uso desta forma de divulgação de seus produtos e/ou serviços, diferindo de negócio a negócio (MULTANI et al., 2013).

Embora a propaganda tenha sempre sido considerada o mais importante instrumento de comunicação de marketing pelo seu grande poder de informar e, especialmente, persuadir, há indica- 
dores de que ela passa por uma crise de credibilidade, o que afeta sua eficácia (CRESCITELLI, 2004). Normalmente, as propagandas são pagas e persuasivas por natureza, realizadas em diversas mídias por anunciantes identificados. Além de promover mercadorias (produtos tangíveis), também ajudam a divulgar os serviços intangíveis oferecidos. Cada vez mais a propaganda é utilizada para defender uma variedade de ideias, sejam elas econômicas, políticas, religiosas ou sociais (ARENS; SCHAEFER; WEIGOLD, 2013).

Com a concorrência acirrada no mercado global, as empresas tentam realizar um trabalho de marketing de relacionamento de maior qualidade, aprendendo que devem ser coerentes entre o que dizem e o fazem. Não é mais suficiente produzir uma propaganda excelente, sendo também necessário que as empresas integrem suas comunicações de marketing com tudo o mais que oferecem. Isso apresenta desafios novos e estimulantes para os profissionais de marketing e propaganda de maneira contínua (ARENS; SCHAEFER; WEIGOLD, 2013).

A propaganda tornou-se a maior forma de arte do século XX, e por isso sentiu-se a necessidade de maior compreensão científica das teorias a ela relacionadas, fazendo com que o ceticismo ficasse cada vez mais em evidência, uma vez que seu fundamento principal se dá pelo questionamento das crenças de um determinado tema, chegando, assim, a respostas ou, ao menos, a um conhecimento maior por parte do público (RIES; RIES, 2002).

Segundo Morel e Pruyn (2003), o ceticismo é uma habilidade necessária, benéfica e saudável que protege os consumidores do engodo dos comerciantes, permitindo fazer avaliações sólidas e objetivas de produtos. O mercado não pode lidar com o ceticismo, mas também nada pode fazer sem ele (OBERMILLER; SPANGENBERG, 1998). As práticas de marketing, muitas vezes caracterizadas por exagero e viés, dependem de algum nível de ceticismo do consumidor. Ao mesmo tempo, na medida em que os consumidores são céticos quanto à veracidade das comunicações de marketing e das ofertas de produtos, o valor da informação é diminuído e os investimentos para comunicar os benefícios de novos produtos aos consumidores são desperdiçados (MOHR; EROGLU; ELLEN, 1998; OBERMILLER; SPANGENBERG, 1998). Além disso, o ceticismo 
pode levar os consumidores a desconfiar de práticas de marketing honestas (MOREL; PRUYN, 2003) e pode levá-los a ignorar ou rejeitar promoções verdadeiramente benéficas (MOHR; EROGLU; ELLEN, 1998). Claramente, tal situação não é do interesse de ninguém. Um estado desejado para os consumidores parece ser aquele em que eles são capazes de decidir quando há necessidade de ser cético (ou seja, quando correm o risco de ser enganados) e quando não existe tal necessidade (ou seja, em situações em que ser cético é contraproducente) (MOREL; PRUYN, 2003).

$\mathrm{O}$ uso da propaganda sem respeito a questões éticas e morais por parte das empresas e a existência de promoções de venda conhecidas como "metade do dobro" vem gerando mensagens que levam à percepção de manipulação, aumentado a resistência à persuasão por parte dos consumidores, fazendo-os encarar as propostas apresentadas com descrença ou diminuindo suas atitudes em relação aos produtos (DIÓGENES; SILVA, 2017).

Wilson, Lindsey, e Schooler (2000) indicaram em seu estudo que atitude pode ser considerado o sentimento das pessoas sobre um objeto, pessoa ou problema, uma tendência psicológica expressa pela avaliação de uma determinada entidade com algum grau de favorecimento ou desfavorecimento. Huertas e Urdan (2009) estudaram a influência da propaganda na atitude e comportamento de compra dos consumidores em relação a medicamentos.

Dados os cenários encontrados na literatura a respeito de ceticismo à propaganda, ceticismo a promoções de vendas e atitude dos consumidores em relação a produtos e serviços, entendeu-se que o estudo das relações entre essas variáveis na área de telefonia móvel, a exemplo do que já fora feito com o marketing verde (BRAGA JUNIOR et al., 2016; DIÓGENES; SILVA, 2017) e medicamentos (HUERTAS; URDAN, 2009), contribuiria para ampliar o conhecimento acerca de como e o quanto essas variáveis se relacionam quando considerado esse tipo de produto. Outrossim, ademais da contribuição teórica complementar aos trabalhos já existentes na literatura (AGUIAR et al., 2015; KETOLA, 2002; MATOS; VEIGA, 2003; SACHER; LOUDON, 2002), o presente estudo se justificaria do ponto de vista mercadológico por auxiliar na orientação de gestores no direcionamento de seus orçamentos para a adequada 
comunicação dos benefícios de seus produtos aos consumidores, buscando evitar que eles desacreditem de práticas honestas ou rejeitem ações realmente salutares. Adicionalmente pesquisou-se a ação de algumas variáveis, possíveis moderadoras, nessas relações, situação não encontrada rotineiramente na literatura, sem contudo elaborar hipóteses por se tratar de proposição exploratória.

\section{REVISÃo DE LITERATURA}

A literatura acadêmica é rica em diversos aspectos no que tange a ceticismo e atitude dos indivíduos, não havendo concentração exclusiva de estudos na área de Marketing.

Skarmeas e Leonidou (2013) definiram que o papel de responsabilidade social das empresas tem sido muito falado nos últimos anos, já que elas fazem contribuições positivas para a sociedade. Porém, isto tem caído em descrédito junto à população, que questiona até que ponto as empresas vivem de acordo com seus padrões e qual o envolvimento ético dos consumidores com a empresa. Buscando testar um modelo que explicasse o ceticismo do consumidor em termos de responsabilidade social empresarial (RSE), os autores realizaram pesquisa cujos resultados revelaram que as atividades com motivações egoístas e produzidas apenas pelo interesse dos acionistas aumentam o ceticismo do consumidor sobre a RSE, enquanto as atividades orientadas para valores inibem tal ceticismo. Da mesma forma, os achados indicaram que o ceticismo sobre RSE prejudica a apreciação do varejista pelo consumidor, diminui a resistência a informações negativas sobre o varejista e estimula o boca-a-boca desfavorável.

Chen e Leu (2011) realizaram pesquisa objetivando visualizar os impactos da propaganda na mensuração da interação de uma marca com seus públicos. As variáveis dependentes neste estudo foram a interação da marca com seus públicos e a intenção de compra. Os resultados mostraram que o ceticismo à propaganda teve efeito negativo sobre a interação da marca com seus públicos e a intenção de compra. No entanto, tais efeitos mostraram-se menos significantes quando testados na presença de interação entre ceticismo à propaganda e o envolvimento com produto. A conclusão dos autores indicou que os efeitos da interação testada (ceticismo 
à propaganda $X$ envolvimento com o produto) podem diluir a influência negativa do ceticismo dos consumidores à propaganda, à marca e à intenção de compra.

Lunardo (2012) realizou pesquisa com o objetivo de abordar o lado negativo da técnica de marketing de lojas varejistas que colocam odores em seus ambientes com o intuito de persuadir os consumidores a comprar mais produtos. Embora tal situação não seja propriamente uma propaganda ou uma promoção de vendas, serve para ilustrar que ações de marketing quaisquer podem desencadear ou incrementar o ceticismo dos consumidores. No experimento, o autor pediu a estudantes de graduação que visitassem uma loja com um determinado perfume ambiente e posteriormente respondessem a um questionário relativo à experiência vivenciada (na realidade o questionário visava medir o grau de ceticismo dos respondentes após sua visita à loja). O resultado indicou que a ausência de qualquer elemento que justificasse um cheiro bom (p. ex.: um forno e um padeiro) induziu significativamente mais ceticismo que a condição na qual havia presença de elementos causadores do bom cheiro (p. ex.: um forno e um padeiro). $\mathrm{O}$ artigo sugere que as características ambientais podem influenciar o ceticismo do consumidor assim como suas respostas emocionais e atitudinais, concluindo por orientar os comerciantes a considerar cuidadosamente o potencial de indução do ceticismo que a atmosfera no interior de sua loja pode ter.

Sher e Lee (2009) desenvolveram um estudo visando testar os efeitos do ceticismo sobre os consumidores online, tendo construído um site de e-commerce para a pesquisa na qual o produto analisado era um telefone celular. Os autores concluíram que consumidores altamente céticos tendem a basear suas atitudes em crenças intrínsecas em vez de fatores situacionais, isto é, eles são tendenciosos contra certos tipos de informação e indiferentes à qualidade da mensagem. Os consumidores com baixo ceticismo tendem a adotar a via periférica na formação da atitude, ou seja, eles são mais persuadidos pela quantidade de argumentos apresentados, independente da consistência de seu conteúdo.

Devido a uma crise alimentar no Reino Unido e a desconfiança das pessoas quanto à produção de alimentos, pesquisadores identificaram a necessidade de realizar uma pesquisa sobre o que os 
consumidores pensam sobre informações alimentares. Eden, Bear, e Walker (2008) realizaram o estudo concluindo que os consumidores tendem a compartilhar uma mesma linha de base para o ceticismo e desconfiança sobre os aspectos de controle e garantia dos alimentos, apesar de diferenças em termos de gênero, dieta e hábitos.

Em Cingapura foi realizado um estudo com o objetivo de analisar o ceticismo da população a informações fornecidas pelos fabricantes de produtos para saúde. Com base nas análises realizadas, os autores concluíram que os cidadãos cingapurianos, em sua grande maioria, são céticos em relação aos dados fornecidos pelos fabricantes e também duvidam da veracidade de muitas informações que estão presentes nas embalagens dos produtos (TAN; TAN, 2007).

Macarthur (2006) desenvolveu um trabalho de cunho mais filosófico a respeito de ceticismo, o ceticismo de Hume (referência a David Hume), tendo como objetivo analisar se as pessoas têm uma boa razão, ou qualquer razão, para acreditar naquilo que defendem, mesmo quando isso não é uma verdade consolidada. Conforme o autor, o principal não é analisar como o ceticismo age em nosso cotidiano, mas sim conhecer e compreender como o ceticismo consegue ser algo tão pessoal e de conhecimento próprio, variando em graus e crenças entre pessoas. Macarthur (2006) concluiu que o ceticismo não é algo que se desenvolve interiormente, mas sim um estado do ser que se desenrola juntamente com a cultura e as crenças.

Austin, Chen, e Grube (2006) desenvolveram estudo com o objetivo de investigar como propagandas persuasivas influenciam os jovens levando-os a crenças e comportamentos de anuência. Os participantes assistiam a comerciais de bebidas alcoólicas e respondiam a um questionário cujos dados eram analisados pelo modelo MIP (Message Interpretation Process). De acordo com esse modelo MIP, os indivíduos internalizam progressivamente as mensagens recebidas usando uma combinação de estratégias de processamento dominadas por lógica e emoção. O modelo mostra como uma emoção positiva pode prejudicar o processamento mais lógico (baseado em dados reais), levando os indivíduos a tirar conclusões com base em pensamentos ilusórios por meio de processamentos afetivos. Os autores concluíram que grande parte dos jovens se sentiu induzida a consumir bebidas alcoólicas após terem visto os comerciais. 
Baseados no crescimento do varejo via e-commerce, pesquisadores sentiram a necessidade de compreender a resposta dos consumidores na formação do preço final de entrega de produtos. Schindler, Morrin, e Bechwati (2005) realizaram um estudo comparando respostas a preços agregados (frete incluído) e desagregados (frete cobrado separadamente) e concluíram que os céticos preferem ofertas comerciais diretas, ou seja, em um formato de preço conjunto enquanto os não céticos preferem o preço desagregado.

Boush, Friestad, e Rose (1994) desenvolveram um estudo com o objetivo de medir o ceticismo dos adolescentes em relação à publicidade e suas crenças sobre as táticas persuasivas que os anunciantes empregam. A pesquisa forneceu fortes evidências de que o ceticismo em relação à publicidade está ligado a variáveis de personalidade e do conhecimento sobre táticas de publicidade do anunciante.

Como pode ser extraído da revisão de literatura, existem vários aspectos estudados sobre ceticismo em relação à propaganda, ceticismo em relação às promoções de venda e atitude em relação ao produto (AMYX; LUMPKIN, 2016; JU, 2017; KIM; KIM; KIM, 2019; LE BORGNE; SIRIEIX; COSTA, 2018; PACHECO; RAHMAN, 2015; PATEL; GADHAVI; SHUKLA, 2017; XUE; HUANG; LIANG, 2019). Assim, julgou-se pertinente propor um modelo teórico unindo esses três fatores, verificando as relações entre eles, assim como fazendo comparações entre subgrupos em função de sexo, idade, tipo de formação educacional, etc. (AGUIAR et al., 2015). Tais proposituras podem ser mostradas na figura 1, assim como resumidas em duas hipóteses:

- $\mathrm{H}_{1}$ : $\mathrm{O}$ ceticismo à propaganda influencia negativa e significantemente a atitude em relação ao produto.

- $\mathrm{H}_{2}$ : $\mathrm{O}$ ceticismo à propaganda influencia positiva e significantemente o ceticismo em relação às promoções de venda. 
Figura 1 - Modelo teórico proposto e hipóteses

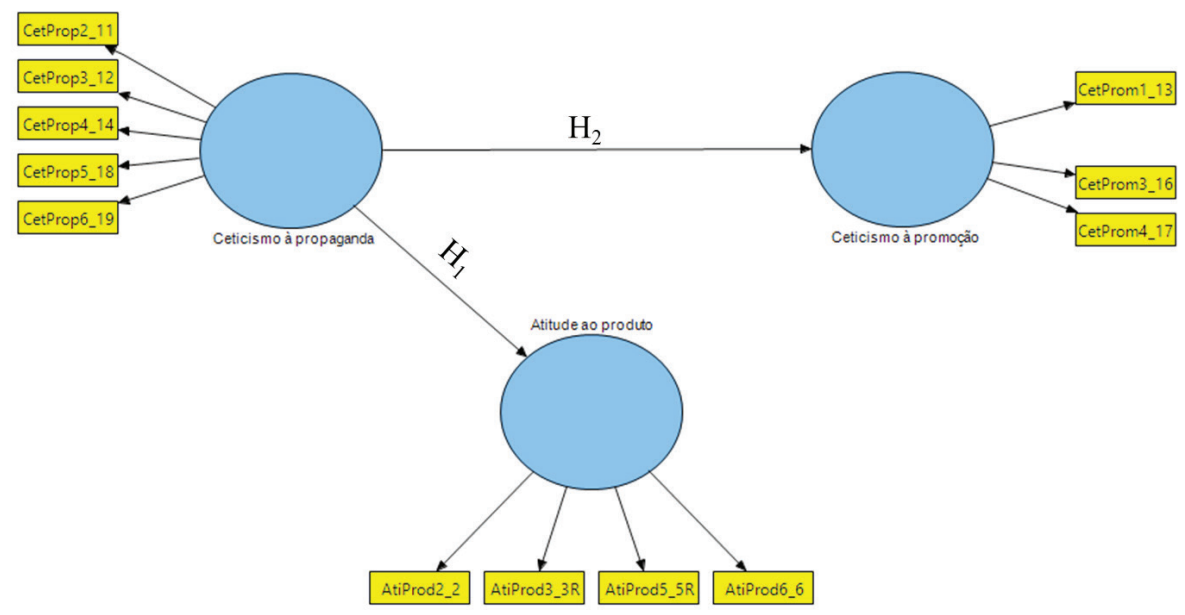

Nota: As variáveis AtiProd3_3 e AtiProd5_5 foram invertidas para se ajustar às demais em sua relação com o construto Atitude em relação ao produto.

Fonte: Elaborado pelos autores.

Em benefício da precisão, os conceitos que embasam as principais variáveis deste estudo se encontram no quadro 1.

Quadro 1 - Variáveis pesquisadas: principais conceitos utilizados no estudo

\begin{tabular}{|ll|}
\hline Variáveis & Definição \\
\hline $\begin{array}{l}\text { Atitude em } \\
\text { relação ao } \\
\text { produto }\end{array}$ & $\begin{array}{l}\text { Sentimento das pessoas sobre um objeto, pessoa ou } \\
\text { problema; uma tendência psicológica que é expressa pela } \\
\text { avaliação de uma determinada entidade com algum grau } \\
\text { de favorecimento ou desfavorecimento (WILSON; LIND- } \\
\text { SEY; SCHOOLER, 2000). }\end{array}$ \\
\hline $\begin{array}{l}\text { Ceticismo } \\
\text { em relação } \\
\text { à propa- } \\
\text { ganda }\end{array}$ & $\begin{array}{l}\text { Tendência geral para a descrença a respeito de afirma- } \\
\text { comercialicitárias por vê-las como exagero de quem }\end{array}$ \\
\hline $\begin{array}{l}\text { Ceticismo } \\
\text { em relação } \\
\text { às promo- } \\
\text { ções de } \\
\text { vendas }\end{array}$ & $\begin{array}{l}\text { Tendência geral para a descrença a respeito de pro- } \\
\text { moçóes de vendas por entender que elas são feitas em }\end{array}$ \\
\hline
\end{tabular}

Fonte: Adaptado de Obermiller e Spangenberg (1998) e Wilson, Lindsey, e Schooler (2000). 


\section{Metodologia}

A presente pesquisa foi realizada de forma quantitativa por meio de respostas obtidas por questionário impresso e distribuído entre alunos de cursos de graduação de quatro universidades / centros universitários (Pontifícia Universidade Católica de São Paulo - PUC_SP, Universidade Presbiteriana Mackenzie - Mackenzie, Centro Universitário FEI - FEI, e Centro Universitário Barão de Mauá - Mauá) nas cidades de São Paulo e São Caetano do Sul, estado de São Paulo, Brasil. Não foram restringidas as participações, podendo colaborar qualquer pessoa que se autodeclarasse estudante do curso de graduação e usuário de aparelho celular, sendo a amostragem realizada por conveniência. Os alunos estavam divididos em anos cursados e a amostra considerou estudantes do primeiro ao sexto ano.

O questionário foi baseado nos trabalhos de Ferraz et al. (2016) e Mohr, Eroglu, e Ellen (1998), adaptando-se as questões relacionadas a atitude em relação ao produto, ceticismo em relação à propaganda e ceticismo em relação às promoções de vendas. Quando necessário, o instrumento de coleta foi traduzido pelos autores (de inglês para português) e em seguida submetido a três professores doutores para avaliação e ajustes. Feitos os ajustes, o questionário foi submetido a 23 universitários da PUC-SP para avaliar a clareza das questões e eventual necessidade de correções para facilitar o entendimento do que se perguntava (validade de face). Em seguida foi feita tradução reversa (de português para inglês) para os itens originalmente redigidos em inglês de modo a assegurar a qualidade da tradução.

As questões foram apresentadas na forma de assertivas com as respostas sendo capturadas por escala tipo Likert de sete pontos, e os respondentes informando seu grau de concordância com o que era apresentado ( 1 - discordo totalmente; 7 - concordo totalmente - apêndice 1). Foi definida a utilização da escala de 7 pontos para aumentar a variância das respostas e melhorar as análises estatísticas a serem feitas (DALMORO; VIEIRA, 2013). No início do questionário o participante visualizava uma breve descrição dos objetivos da pesquisa e informações sobre a confidencialidade das respostas.

Os dados foram analisados por Modelagem de Equações Estruturais (MEE) com uso do método de Mínimos Quadrados Parciais 
(Partial Least Squares - Structured Equation Modeling - PLS-SEM) utilizando o software SmartPLS (www.smartpls.de). Esse método é utilizado principalmente nos campos de pesquisa das ciências sociais e marketing, e é indicado para amostras menores cujas distribuições não são normais (RINGLE; DA SILVA; BIDO, 2014; WONG, 2013). Além disso, de acordo com Wong (2013), o software cria uma representação visual das associações que facilita a interpretação dos resultados quando se estudam diversos construtos. O modelo proposto para esse mapeamento estatístico investigou as associações entre os três construtos mencionados anteriormente (atitude em relação ao produto, ceticismo em relação à propaganda e ceticismo em relação às promoções de vendas, sendo possível identificar tais associações com base em coeficientes de caminho e sua respectiva significância.

Paralelamente à construção do modelo e avaliação dos coeficientes de caminho, foram feitos testes para verificar a confiabilidade e validade das escalas utilizadas para garantir que os instrumentos usados eram adequados para as mensurações que se desejava fazer (WONG, 2013). Por fim, foram identificados subgrupos dentro da amostra analisada e feitos testes de comparação entre eles para observar possíveis diferenças no modelo proposto para grupos distintos dentro da população de estudantes.

\section{Análise dos Resultados}

Foram obtidas 304 respostas ao questionário, número que, segundo Wong (2013), atinge o mínimo necessário para seguir com a análise PLS-SEM. As tabelas 1 e 2 mostram o perfil dos respondentes.

Tabela 1 - Perfil dos participantes

\begin{tabular}{lll}
\hline Sexo & Frequência & Porcentagem \\
\hline Masculino & 167 & $54.9 \%$ \\
Feminino & 137 & $45.1 \%$ \\
Total & 304 & $100.0 \%$ \\
\hline \hline Ano cursado & Frequência & Porcentagem \\
\hline
\end{tabular}




\begin{tabular}{lll}
\hline 1o. ano & 40 & $13.2 \%$ \\
2o. ano & 52 & $17.1 \%$ \\
3o. ano & 41 & $13.5 \%$ \\
4o. ano & 37 & $12.2 \%$ \\
5o. ano & 91 & $29.9 \%$ \\
6o. ano & 43 & $14.1 \%$ \\
Total & 304 & $100.0 \%$ \\
\hline & & \\
\hline Idade & Frequência & Porcentagem \\
\hline $15-20$ anos & 92 & $30.3 \%$ \\
$21-25$ anos & 104 & $34.2 \%$ \\
$26-30$ anos & 60 & $19.7 \%$ \\
$31-35$ anos & 22 & $7.2 \%$ \\
36 anos ou mais & 26 & $8.6 \%$ \\
Total & 304 & $100.0 \%$ \\
\hline
\end{tabular}

Fonte: Elaborado pelos autores.

Considerando a tabela 1 observa-se que a representatividade de homens e mulheres nessa amostra, de 54,9\% e $45,1 \%$ respectivamente, é praticamente igual. Um aspecto que intrigava era se os dois grupos teriam comportamentos diferentes no ajuste do modelo teórico proposto, o que foi verificado em etapas posteriores à presente análise. A maior parte dos respondentes estava na segunda metade do curso (43,8\% do primeiro ao terceiro ano e $56,3 \%$ do quarto ao sexto). Isto também poderia ser uma fonte de diferença no resultado do modelo, o que foi verificado em fases posteriores do estudo. Quanto à idade, 64,5\% dos respondentes tinham 25 anos ou menos enquanto $35,5 \%$ estava acima desse limite, se constituindo tal característica em possível causadora de mudança na adequação do modelo, o que foi verificado em etapas posteriores da análise. 
Tabela 2 - Perfil dos participantes

\begin{tabular}{|c|c|c|}
\hline Escola & Frequência & Porcentagem \\
\hline PUC-SP & 147 & $48.4 \%$ \\
\hline Mackenzie & 129 & $42.4 \%$ \\
\hline FEI & 9 & $3.0 \%$ \\
\hline Mauá & 19 & $6.3 \%$ \\
\hline Total & 304 & $100.0 \%$ \\
\hline Formação & Frequência & Porcentagem \\
\hline Exatas & 197 & $64.8 \%$ \\
\hline Humanas & 107 & $35.2 \%$ \\
\hline Total & 304 & $100.0 \%$ \\
\hline Origem & Frequência & Porcentagem \\
\hline Cidade de São Paulo & 219 & $72.0 \%$ \\
\hline Outras cidades & 85 & $28.0 \%$ \\
\hline Total & 304 & $100.0 \%$ \\
\hline Troca de aparelho & Frequência & Porcentagem \\
\hline 7 a 12 meses & 25 & $8.2 \%$ \\
\hline 13 a 18 meses & 94 & $30.9 \%$ \\
\hline 19 a 24 meses & 82 & $27.0 \%$ \\
\hline 25 a 30 meses & 70 & $23.0 \%$ \\
\hline 31 a 36 meses & 18 & $5.9 \%$ \\
\hline 37 a 42 meses & 6 & $2.0 \%$ \\
\hline 43 meses ou mais & 9 & $3.0 \%$ \\
\hline Total & 304 & $100.0 \%$ \\
\hline
\end{tabular}

Fonte: Elaborado pelos autores.

A tabela2 complementa as informações sobre o perfil dos respondentes. No que diz respeito à escola na qual os respondentes 
estudavam, 90,8\% deles se distribuíam de maneira relativamente equilibrada entre Mackenzie e PUC-SP. Em função das características dessas duas escolas optou-se por verificar se para cada uma delas haveria diferenças no ajuste do modelo proposto, o que foi feito em etapas posteriores da análise. Formação e origem (naturalidade do respondente) apresentaram valores bastante diferentes, sendo que a maior incidência na formação dos respondentes foi na área de exatas $(64,8 \%)$ e 72,0\% deles eram originários da cidade de São Paulo. Tais diferenças suscitaram interesse em verificar se haveria diferenças significantes entre cada um dos grupos quanto ao ajuste do modelo proposto, o que foi verificado em etapas posteriores da análise. Quanto ao tempo de troca do aparelho, 66,1\% dos respondentes faziam a troca em prazo igual ou inferior a dois anos. Tal situação inspirou a comparação entre grupos (menos de ou igual a dois anos vs. mais de dois anos) quanto ao ajuste do modelo proposto, o que foi feito em etapas posteriores da análise.

Seguindo Wong (2013), o modelo teórico proposto foi inicialmente avaliado quanto ao carregamento dos itens em cada construto (carregamento cruzado), confiabilidade composta, validade convergente e validade discriminante.

Cargas fatoriais são a correlação de cada variável medida (indicador ou assertiva) com o fator (construto) a ela relacionado, indicando o grau de correspondência entre as variáveis mensuráveis e o fator. Cargas fatoriais são o meio de interpretar o papel que cada variável tem na definição do fator e cargas maiores tornam a variável mais representativa do fator (HAIR et al., 2009). A análise de carregamento cruzado indica se cada variável está associada a um único fator ou se há ocorrência de cargas cruzadas, quando uma variável tem duas ou mais cargas fatoriais excedendo um valor de referência assumido, considerado necessário para inclusão no processo de interpretação do fator (Hair et al., 2009; Hair et al., 2014). A referida análise tem caráter tanto qualitativo (alinhamento de cada variável a seu respectivo fator) como quantitativo (valor da carga fatorial de uma variável em um determinado fator).

Como mostrado na tabela 3, ao final das análises todos os itens carregados em seus respectivos construtos apresentaram cargas fatoriais maiores do que suas cargas em outros fatores. Durante a 
análise, as questões que não apresentaram aderência mínima aceitável nos ajustes do modelo foram removidas (HAIR et al., 2009). Nesta análise também se tem um indicativo precoce da validade discriminante das escalas (RINGLE; DA SILVA; BIDO, 2014), o que foi ratificado por outros testes.

Tabela 3 - Carregamento cruzado final

\begin{tabular}{cccc}
\hline & Atitude ao produto & Ceticismo às promoções & Ceticismo à propaganda \\
\hline AtiProd2_2 & $\mathbf{0 . 5 3 6}$ & 0.412 & -0.147 \\
AtiProd5_5R & $\mathbf{0 . 7 6 7}$ & 0.384 & -0.339 \\
AtiProd6_6 & $\mathbf{0 . 9 2 6}$ & -0.025 & -0.648 \\
CetProm1_13 & 0.096 & $\mathbf{0 . 1 8 6}$ & -0.053 \\
CetProm3_16 & 0.133 & $\mathbf{0 . 8 2 7}$ & 0.161 \\
CetProm4_17 & 0.198 & $\mathbf{0 . 9 5 6}$ & 0.316 \\
CetProp2_11 & -0.434 & 0.134 & $\mathbf{0 . 6 1 5}$ \\
CetProp3_12 & -0.527 & 0.112 & $\mathbf{0 . 8 4 7}$ \\
CetProp4_14 & -0.454 & 0.017 & $\mathbf{0 . 7 8 0}$ \\
CetProp5_18 & -0.361 & 0.608 & $\mathbf{0 . 7 9 6}$ \\
CetProp6_19 & -0.501 & 0.171 & $\mathbf{0 . 7 6 3}$ \\
\hline
\end{tabular}

Nota: Os números em negrito são as cargas dos indicadores em seus respectivos construtos; os demais números são as cargas cruzadas

Fonte: Elaborado pelos autores.

A Tabela 4 resume as métricas de validade convergente (AVE) e confiabilidade composta (CC) das escalas. De acordo com as diretrizes propostas por Byrne (2010), as escalas utilizadas nesse estudo apresentaram parâmetros considerados apropriados (AVE $>0,5 ; \mathrm{CC}>0,7)$.

Tabela 4 - AVE (validade convergente) e CC (confiabilidade composta)

\begin{tabular}{lll}
\hline & $\begin{array}{l}\text { Validade } \\
\text { Convergente (AVE) }\end{array}$ & $\begin{array}{l}\text { Confiabilidade } \\
\text { Composta (CC) }\end{array}$ \\
\hline Atitude ao produto & 0.578 & 0.797 \\
Ceticismo às promoções & 0.544 & 0.739 \\
Ceticismo à propaganda & 0.584 & 0.874 \\
\hline
\end{tabular}

Fonte: Elaborado pelos autores. 
Para verificação da validade discriminante das escalas foi seguido o procedimento recomendado por Fornell e Larcker (1981), comparando-se a raiz quadrada da variância média extraída (AVE) com a correlação de Pearson verificada entre as escalas usadas para representar os construtos. Em havendo validade discriminante, as correlações teriam valores menores do que a raiz quadrada das AVE das escalas. A Tabela 5 demonstra a existência de validade discriminante considerando-se este critério.

Tabela 5 - Validade discriminante dos construtos

\begin{tabular}{llll}
\hline & $\begin{array}{l}\text { Atitude ao } \\
\text { produto }\end{array}$ & $\begin{array}{l}\text { Ceticismo } \\
\text { às promo- } \\
\text { ções }\end{array}$ & $\begin{array}{l}\text { Ceticismo à } \\
\text { propaganda }\end{array}$ \\
\hline Atitude ao produto & $\mathbf{0 . 7 6 0}$ & & \\
Ceticismo às promoções & 0.186 & $\mathbf{0 . 7 3 7}$ & \\
Ceticismo à propaganda & -0.593 & 0.302 & $\mathbf{0 . 7 6 4}$ \\
\hline
\end{tabular}

Nota: Os números em negrito na diagonal são a raiz quadrada das AVE, para cada escala.

Fonte: Elaborado pelos autores.

Antes de partir para a análise do modelo causal adotou-se procedimento para avaliar a sensibilidade da coleta realizada ao viés do método comum, e a consequente presença de variância gerada pelo método comum. Viés do método comum é um fenômeno passível de ocorrer devido ao uso de um único instrumento de coleta para recolher as informações em campo, todas reunidas em um mesmo momento, trazendo consigo o risco de influenciar o processo de resposta via erro sistemático (CASALÓ; FLAVIÁN; GUINALÍU, 2010; PODSAKOFF et al., 2003; PODSAKOFF; ORGAN, 1986). Foram feitos dois testes: o primeiro, pela abordagem da correlação parcial, recomendado por Lindell e Whitney (2001) e usado em estudos como os desenvolvidos por Jarvenpaa e Majchrzak (2008) e os mencionados por Richardson, Simmering e Sturman (2009). O segundo teste envolveu a abordagem da colinearidade completa, proposto por Kock (2015). No presente trabalho, as abordagens mencionadas indicaram a não existência da variância do método comum, evidenciando a qualidade dos dados coletados. 
Seguindo à análise estatística das relações entre os construtos envolvidos no modelo teórico, primeiramente considerou-se a amostra geral de 304 respondentes. A Figura 2 mostra o resultado do modelo de equação estrutural gerado pelo software SmartPLS.

Figura 2 - Modelo teórico final para a amostra geral

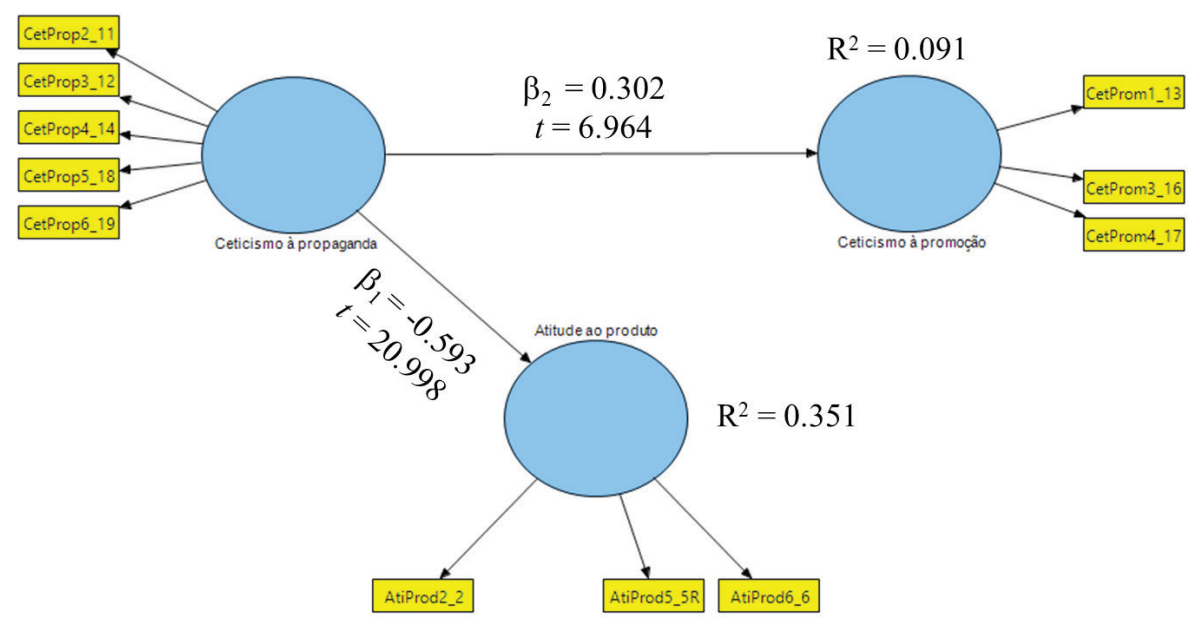

Fonte: Elaborado pelos autores.

A Tabela 6 mostra os resultados do modelo estrutural com os coeficientes de caminho estimados e os valores $t$ associados de cada caminho, indicando que todos são significantes $(t>1,96)$, o que equivale a dizer que o ceticismo em relação à propaganda influencia negativamente a atitude do respondente em relação ao produto. Da mesma forma, o ceticismo em relação à propaganda tem influência sobre o ceticismo em relação às promoções de vendas, sendo tal influência, entretanto, positiva. Assim, as duas hipóteses formuladas inicialmente foram suportadas pelos dados coletados e pelas análises realizadas. 
Tabela 6 - Modelo estrutural - coeficientes de caminho

\begin{tabular}{llc}
\hline & Coeficiente de caminho & Valor $\boldsymbol{t}$ \\
\hline $\begin{array}{l}\text { Ceticismo à propaganda } \rightarrow \text { Atitude ao } \\
\text { produto }\end{array}$ & -0.593 & 20.998 \\
$\begin{array}{l}\text { Ceticismo à propaganda } \rightarrow \text { Ceticismo } \\
\text { às promoções }\end{array}$ & 0.302 & 6.964 \\
\hline
\end{tabular}

Fonte: Elaborado pelos autores.

O modelo responde por $35.1 \%$ da variância de atitude em relação produto $\left(R^{2}\right)$ e $9,1 \%$ da variância de ceticismo em relação às promoções de vendas, valores considerados, respectivamente, como de efeito grande e de efeito pequeno, conforme indicado por Ringle et al. (2014) Tais valores indicam a capacidade de explicação do modelo a respeito das relações entre os construtos. A análise mais detalhada dos coeficientes de caminho mostra que, em uma escala de maior para menor influência, ceticismo à propaganda tem influência maior, embora negativa, sobre atitude em relação ao produto do que sobre ceticismo às promoções de vendas.

Dando sequência, foram avaliados os valores de dois outros indicadores de qualidade de ajuste do modelo: relevância ou validade preditiva $\left(\mathrm{Q}^{2}\right)$ e tamanho do efeito $\left(\mathrm{f}^{2}\right)$ (RINGLE; DA SILVA; BIDO, 2014). Chin (1998) afirma que o $\mathrm{R}^{2}$ para cada variável latente pode ser um ponto de partida quando da análise PLS para o modelo estruturado, uma vez que a interpretação do PLS é semelhante à de uma análise de regressão tradicional. $\mathrm{O}$ autor também afirma que a mudança no $\mathrm{R}^{2}$ pode ser explorada para ver se o impacto de uma variável latente independente específica em uma variável latente dependente é substancial. No caso do presente trabalho, o tamanho do efeito $\left(\mathrm{f}^{2}\right)$ não foi determinado por só haver uma variável independente no modelo. Os valores de $\mathrm{Q}^{2}$ são calculados para identificar a validação cruzada e consequentemente, a relevância preditiva do modelo. $\mathrm{Q}^{2}>0$ implica em que o modelo tem relevância preditiva e $\mathrm{Q}^{2}<0$ representa falta de relevância preditiva. 
Tabela 7 - Validade preditiva $\left(Q^{2}\right)$ e tamanho do efeito $\left(f^{2}\right)$ do modelo teórico final

\begin{tabular}{lll}
\hline & $\mathrm{Q}^{2}$ & $\mathrm{f}^{2}$ \\
\hline Atitude ao produto & 0.165 & \\
Ceticismo às promoções & 0.034 & \\
Ceticismo à propaganda & & $\mathrm{ND}$ \\
\hline
\end{tabular}

Nota: Como ceticismo em relação à propaganda é o único construto exógeno do modelo, omiti-lo para calcular o $\mathrm{f}^{2}$ desmontaria a estrutura proposta, daí tal valor não ter sido determinado (ND).

Fonte: Elaborado pelos autores.

A tabela 7 mostra valor de $\mathrm{Q}^{2}$ positivo o que indica o quanto o modelo se aproxima do que se esperava dele e, consequentemente, sua qualidade de predição (valores negativos implicariam em falta de relevância preditiva).

Feitas essas análises realizou-se a comparação de resultados entre determinados subgrupos da amostra principal. Tal procedimento é chamado análise multigrupo e é usado para comparar parâmetros (geralmente os coeficientes de caminho) entre dois ou mais grupos de dados. Normalmente é aplicado quando se deseja explorar diferenças que podem ser rastreadas até características observáveis, como gênero ou país de origem. Nessa situação, presume-se que exista uma variável moderadora categórica (por exemplo, sexo) que influencie as relações no modelo estrutural global desenvolvido. $\mathrm{O}$ objetivo da análise multigrupo é, portanto, revelar o efeito da variável moderadora categórica em questão. Quando as verdadeiras fontes de heterogeneidade em conjuntos de dados são desconhecidas, a heterogeneidade é considerada não observada (HAIR et al., 2014; VINZI et al., 2010).

As diferenças entre os coeficientes de caminho são testadas quanto à significância com um teste $t$, usando para tal a equação a seguir (HAIR et al., 2014; VINZI et al., 2010):

$$
t=\frac{\text { Coeficiente }_{\text {grupo } 1}-\text { Coeficiente }_{\text {grupo } 2}}{\sqrt{\frac{(m-1)^{2}}{(m+n+2)} * e p_{\text {grupo } 1}^{2}+\frac{(n-1)^{2}}{(m+n-2)} * e p_{\text {grupo } 1}^{2}} * \sqrt{\frac{1}{m}+\frac{1}{n}}}
$$


na qual

- Coeficiente grupo $1 / 2_{\text {: }}$ estimativa do coeficiente de caminho da amostra global para os subgrupos considerados, respectivamente;

- m: número de casos do grupo 1

- n: número de casos do grupo 2

- $\quad \mathrm{ep}_{\text {grupo } / 2}$ : erro padrão do coeficiente de caminho em ambos os subgrupos, respectivamente (obtidos a partir do procedimento de reamostragem - bootstrapping - executado no SmartPLS para cada grupo).

No presente artigo foram testadas as seguintes variáveis para a geração dos subgrupos: sexo (homens vs. mulheres), tempo de curso (primeira metade $-1^{\underline{0}}$ ao $3^{\mathrm{o}}$ ano - vs. segunda metade $-4^{\mathrm{o}}$ ao $6^{\text {o }}$ ano), idade (até 25 anos vs. maior que 25 anos), escola (PUC-SP vs. Mackenzie), formação (exatas vs. humanas), origem do respondentes (cidade de São Paulo vs. outras cidades) e frequência de troca do aparelho celular (até dois anos vs. mais de dois anos). Tal escolha se deveu ao pressuposto de que as relações entre os construtos em estudo (ceticismo à propaganda, ceticismo às promoções de vendas e atitude em relação ao produto) poderiam ser afetadas por aspectos econômicos, sociais, culturais, nível de amadurecimento dos alunos e modelo de ensino adotado pela escola na qual o respondente estudava (ARAUJO; ARRAES, 2001), assim como por trabalhos desenvolvidos anteriormente e que mostravam que tais variáveis poderiam ser causa de diferença de atitudes frente ao uso de celulares (AGUIAR et al., 2015), assim como de comportamento cético (AUSTIN; CHEN; GRUBE, 2006; BOUSH; FRIESTAD; ROSE, 1994). Embora tais variáveis possam estar fortemente interligadas na rotina das pessoas, foram aqui avaliadas separadamente, visando fornecer maior clareza a respeito de sua interferência nas relações estudadas.

Na tabela 8 são mostrados os resultados das comparações propostas e sua respectiva significância. 
Tabela 8 - Análise multigrupo - comparação ente subgrupos componentes da amostra geral

\begin{tabular}{|c|c|c|c|c|}
\hline \multirow[t]{2}{*}{$\begin{array}{l}\text { Multigrupos ana- } \\
\text { lisados }\end{array}$} & \multicolumn{2}{|c|}{$\begin{array}{l}\text { Ceticismo à propaganda } \rightarrow \\
\text { Atitude ao produto }\end{array}$} & \multicolumn{2}{|c|}{$\begin{array}{l}\text { Ceticismo à propaganda } \\
\rightarrow \text { Ceticismo às promo- } \\
\text { ções }\end{array}$} \\
\hline & Coeficiente & $t$ & Coeficiente & $t$ \\
\hline Homens & -0.6063 & \multirow{2}{*}{ NS } & 0.3576 & \multirow{2}{*}{ NS } \\
\hline Mulheres & -0.5945 & & 0.2471 & \\
\hline $\begin{array}{l}\text { 1a. metade do } \\
\text { curso }\end{array}$ & -0.6688 & \multirow{2}{*}{-3.082} & 0.7115 & \multirow{2}{*}{ NS } \\
\hline $\begin{array}{l}\text { 2a. metade do } \\
\text { curso }\end{array}$ & -0.4367 & & 0.5936 & \\
\hline Idade até 25 anos & -0.7357 & \multirow[b]{2}{*}{ NS } & 0.6668 & \multirow[b]{2}{*}{ NS } \\
\hline $\begin{array}{l}\text { Idade maior que } \\
25 \text { anos }\end{array}$ & -0.5469 & & 0.7943 & \\
\hline PUC-SP & -0.6917 & \multirow{2}{*}{ NS } & 0.2254 & \multirow{2}{*}{-3.734} \\
\hline Mackenzie & -0.6051 & & 0.5239 & \\
\hline Exatas & -0.7252 & \multirow{2}{*}{ NS } & 0.4592 & \multirow{2}{*}{3.768} \\
\hline Humanas & -0.7588 & & 0.1641 & \\
\hline$\overline{\text { Origem São Paulo }}$ & -0.6095 & \multirow[b]{2}{*}{ NS } & 0.2605 & \multirow[b]{2}{*}{ NS } \\
\hline $\begin{array}{l}\text { Origem outras } \\
\text { cidades }\end{array}$ & -0.6178 & & 0.3813 & \\
\hline $\begin{array}{l}\text { Troca de aparelho } \\
\text { em até } 2 \text { anos }\end{array}$ & -0.6210 & \multirow[b]{2}{*}{ NS } & 0.2481 & \multirow[b]{2}{*}{-2.395} \\
\hline $\begin{array}{l}\text { Troca de apare- } \\
\text { lho em mais de } 2 \\
\text { anos }\end{array}$ & -0.5842 & & 0.4619 & \\
\hline
\end{tabular}

Nota: Valores de $t$ menores de 1,96 foram considerados não significantes (NS) para um nível de confiança de $95 \%$.

Fonte: Elaborado pelos autores.

Como pode ser verificado, não há diferença estatisticamente significante entre os coeficientes de caminho estimados para os itens sexo (homens vs. mulheres), idade (até 25 anos vs. maior que 25 anos) e origem do respondente (cidade de São Paulo vs. outras cidades). Assim, pode-se dizer que, independente de sexo, idade e origem do respondente, a influência do ceticismo à propaganda 
sobre atitude em relação ao produto e do ceticismo à propaganda sobre ceticismo às promoções de vendas é, estatisticamente, a mesma, não podendo as variáveis geradoras dos subgrupos serem consideradas como moderadoras no modelo proposto (HAIR et al., 2014; VINZI et al., 2010).

Entretanto, o mesmo não pode ser dito a respeito das demais variáveis escolhidas. Pela análise da tabela 8 verifica-se que os respondentes que estão na segunda metade do curso de graduação tendem a ter influência negativa menor do ceticismo à propaganda sobre a atitude em relação ao produto. Como entende-se por ceticismo o sentimento de descrença que é característica intrínseca dos indivíduos e é influenciado pelos seus traços e experiências (DIÓGENES; SILVA, 2017), eventualmente as experiências vivenciadas durante o curso podem ter dado aos respondentes maiores informações a respeito da propaganda e sua utilidade na fidelização de clientes, fazendo com que a influência do ceticismo à propaganda seja menor sobre sua atitude em relação ao produto (menor valor negativo do coeficiente de caminho ceticismo à propaganda @ atitude ao produto).

Algumas pesquisas têm demonstrado a influência que programas pedagógicos e orientação educacional das escolas têm sobre os alunos em aspectos como desenvolvimento de atitudes sustentáveis, participação em programas de reciclagem, interesse por programas sobre sustentabilidade e economia no uso de água (COSTA et al., 2000; JACOMOSSI; MORANO; BARRICHELLO, 2014), assim como sobre o perfil das escolhas dos estudantes em suas carreiras (AZEVEDO et al., 2012; GRADVOHL; LOPES; COSTA, 2009). Quando se analisa os dados da tabela 8, conclusão semelhante pode ser tirada sobre as variáveis escola (PUC-SP vs. Mackenzie) e formação (exatas vs. humanas) quanto à influência que o ceticismo à propaganda tem em relação ao ceticismo às promoções de vendas. Os valores dos coeficientes de caminho estimados mostram que, para os alunos do Mackenzie e para aqueles com formação em Exatas, tal influência é mais intensa. Tal situação não implica em necessidade de mudanças no processo de formação dos alunos e sua associação às competências relacionais inerentes ao Marketing (MORAIS; SOUZA, 2015), mas indica que tanto escola quanto formação mostraram-se com ação moderadora no modelo construído. 
Por fim, fica evidenciada a ligação da relação ceticismo à propaganda ceticismo às promoções de vendas, com a frequência de troca do aparelho celular (até dois anos vs. mais de dois anos), uma vez que tal relação é mais intensa (maior valor do coeficiente de caminho) para os respondentes que trocam seus celulares em períodos maiores do que dois anos. Tal resultado corrobora o trabalho de Karjaluoto et al. (2005) que afirmam que embora problemas técnicos sejam a razão básica para a troca de celular entre os estudantes, sendo preço, marca, interface e propriedades também fatores influentes que afetam a escolha real entre as marcas, tal escolha é de natureza subjetiva, podendo ser influenciada pelo ceticismo.

Considerando todos os resultados analisados, conclui-se que o modelo teórico proposto é válido, podendo ser utilizado para compreender as relações entre ceticismo à propaganda, ceticismo às promoções de vendas e atitude em relação ao produto, tanto para o conjunto da amostra estudada como para alguns subgrupos considerados.

\section{Conclusões}

O objetivo principal desta pesquisa foi estudar as relações entre o ceticismo à propaganda, ceticismo às promoções de vendas e atitude em relação ao produto, todas consideradas na área de telefonia celular. Complementarmente trabalhou-se subgrupos dentro da amostra principal para verificar se o resultado global se reproduziria para grupos específicos. Para atingir esse intento foi proposto um modelo teórico com base em dados adaptados da literatura e as relações entre as variáveis foram estudadas por MEE. As escalas de mensuração usadas foram adaptadas de instrumentos existentes na literatura de ceticismo, de propaganda e de atitude em relação a produtos e serviços e que já tinham sido devidamente validados. A despeito desta validação prévia, as escalas foram testadas quanto à qualidade de suas características psicométricas de modo que isso não fosse uma fonte de erro de análise e conclusão.

Embora existam muitos trabalhos que abordem o tema de ceticismo em relação à propaganda e atitudes/comportamentos de consumidores (AUSTIN; CHEN; GRUBE, 2006; BOUSH; FRIESTAD; ROSE, 1994; CHEN; LEU, 2011; DIÓGENES; SILVA, 2017; HUER- 
TAS; URDAN, 2009; OBERMILLER; SPANGENBERG, 1998; TAN; TAN, 2007), poucos são os que se dedicam em detalhes ao ceticismo em relação às promoções de vendas e que analisam subgrupos dentro de uma amostra principal, como o que foi realizado no presente estudo. Isto mostra as contribuições acadêmicas trazidas pelo trabalho por explorar aspectos que nem sempre são tratados pela literatura, assim como as contribuições gerenciais por ampliar o conhecimento acerca do quanto as medidas de persuasão presentes nas propagandas e promoções de venda podem influenciar diferentes grupos de consumidores.

Os resultados do modelo estrutural mostraram relação negativa e significante entre o ceticismo à propaganda e a atitude em relação ao produto, o que significa dizer que quanto maior for o ceticismo, pior será a atitude em relação ao produto.

Embora Macarthur (2006) e Boush, Friestad, e Rose (1994) afirmem que o ceticismo é algo pessoal e de conhecimento próprio, ligado a variáveis de personalidade, e Obermiller e Spangenberg (1998) deem indicação de que nada pode ser feito contra ele, o trabalho de Lunardo (2012) deixa claro que tentativas de ludibriar o cliente só servem para aumentar seu ceticismo. O presente trabalho dá indicações quanto aos procedimentos que fabricantes e comerciantes de aparelhos celulares devem ter frente aos consumidores, evitando tomar ações publicitárias que aumentem a insatisfação e a desconfiança dos consumidores, aumentando seu ceticismo e prejudicando sua atitude em relação aos produtos e serviços comercializados.

Fornecedores necessitam de feedback de seus clientes para melhorar sua oferta ao mercado em termos de produtos e serviços (PARRA; AMATRIAIN, 2011). A maioria das abordagens para entender as preferências ou o gosto do usuário baseia-se em seus comentários explícitos. No entanto, em muitas situações, é necessário contar com feedback implícito, como a quantidade de vezes que um usuário compra um item ou escuta uma música. Isso se dá porque nem sempre o que o cliente diz é o que ele pensa, trazendo à tona a expressão inglesa walk the talk, que significa "alinhar o discurso com a ação" (PARRA; AMATRIAIN, 2011). De forma semelhante, os clientes esperam o mesmo de seus fornecedores e sempre que houver desconexão entre esses dois pontos o ceticismo do cliente 
tenderá a aumentar (SKARMEAS; LEONIDOU, 2013), trazendo prejuízo para a atitude que ele tem em relação a produtos e serviços, como mostrado no presente trabalho. Assim, embora controlar o ceticismo seja difícil em função da pessoalidade que caracteriza tal construto, fornecedores podem minimizá-lo na medida em que exercerem o walk the talk.

Outros resultados mostraram relação positiva e significante entre o ceticismo à propaganda e o ceticismo às promoções de vendas, o que significa dizer que quanto maior for o ceticismo em relação a uma, maior será o ceticismo em relação à outra. Tal situação reforça o que foi afirmado anteriormente pois promoções de vendas podem ser inúteis e contraproducentes na medida em que os clientes não acreditem nas propagandas dos fornecedores e, em consequência, em suas promoções de vendas. Novamente a necessidade do walk the talk se faz presente, e sua ausência gerará perda de negócios e oportunidades.

As relações verificadas para toda a amostra apresentaram-se similares quando uma série de subgrupos foram designados para análise específica, a saber: sexo (homens vs. mulheres), tempo de curso (primeira metade $-1^{\underline{o}}$ ao $3^{\underline{o}}$ ano - vs. segunda metade $-4^{\underline{o}}$ ao $6^{\circ}$ ano), idade (até 25 anos vs. maior que 25 anos), escola (PUC-SP vs. Mackenzie), formação (exatas vs. humanas), origem do respondentes (cidade de São Paulo vs. outras cidades) e frequência de troca do aparelho celular (até dois anos vs. mais de dois anos). A despeito disto puderam ser verificadas diferenças de intensidade nas relações estudadas. Por exemplo, embora a relação entre ceticismo à propaganda e atitude em relação ao produto tenha se apresentado negativa para todos os subgrupos, quando a influência do tempo de curso foi analisada (primeira metade $-1^{\underline{0}}$ ao $3^{\circ}$ ano - vs. segunda metade $-4^{\circ}$ ao $6^{\circ}$ ano) observou-se que para os alunos da primeira metade do curso a intensidade era maior do que para alunos da segunda metade do curso. Pode-se inferir disto que eventualmente as experiências vivenciadas durante o curso possam dar aos respondentes maiores informações a respeito de propaganda e sua utilidade na fidelização de clientes, fazendo com que a influência do ceticismo à propaganda seja menor sobre a atitude em relação ao produto para os alunos da segunda metade do curso. 
Diferenças entre os subgrupos também foram verificadas quando da análise da relação ceticismo à propaganda e ceticismo às promoções de vendas. Embora todas tenham sido positivas e significantes, quando se comparou escola (PUC-SP vs. Mackenzie), a intensidade da relação foi maior para os respondentes do Mackenzie do que para os da PUC-SP. A mesma característica foi verificada quanto a formação (exatas vs. humanas). Pode-se inferir daí que programas pedagógicos e orientação educacional das escolas, e o perfil nas escolhas dos estudantes em suas carreiras tem influência na relação entre as variáveis consideradas.

Por fim, a frequência de troca do aparelho celular (até dois anos vs. mais de dois anos) também mostrou influência sobre a relação entre ceticismo à propaganda e ceticismo às promoções de vendas, mostrando que esta relação é mais intensa para aqueles que trocam seus aparelhos com menor regularidade. Em síntese, o ceticismo às promoções de vendas parece ser mais influenciado pelo ceticismo à propaganda para determinadas pessoas, fazendo-as trocar seus aparelhos mais esporadicamente.

Pelo exposto, acredita-se que o trabalho trouxe contribuições para o melhor entendimento das relações entre ceticismo à propaganda, ceticismo às promoções de vendas e atitude em relação ao produto, cumprindo com os objetivos propostos pelos autores.

Por fim, diante dos resultados alcançados, algumas questões de ordem gerencial podem ser suscitadas, sendo base para futuros estudos. Considerando que o ceticismo à propaganda influencia o ceticismo às promoções de vendas, seria lícito pensar em fazer maiores investimentos em uma estratégia em detrimento da outra ? Low e Mohr (2000) relataram que seus estudos fornecem aos profissionais de marketing e publicidade uma nova perspectiva que pode incentivá-los a gerenciar mais estrategicamente o processo de alocação de orçamento de comunicações de marketing. Questionaram os autores se os produtos na fase madura de seu ciclo de vida deveriam receber mais gastos com promoção de vendas via desconto e menos publicidade do que as novas marcas. Os resultados aqui obtidos podem fornecer pavimento a futuros estudos focados nesta dicotomia de investimento.

Complementarmente, em função dos diferentes resultados obtidos para escolas com diferente orientação pedagógica e curso 
com finalidade diversa, seria recomendável aprofundar a pesquisa nestes quesitos para verificar a reprodutibilidade em outros cenários do que foi aqui verificado.

\section{REFERÊNCIAS}

AGUIAR, F. H. O. et al. Avaliação da Usabilidade de Telefones Celulares no Mercado Brasileiro: Gênero, Idade, Escolaridade e Renda Familiar têm Alguma Influência? Revista de Administração IMED, v. 4, n. 2, p. 144-160, 2015.

AMYX, D. A.; LUMPKIN, J. R. Interaction Effect of Ad Puffery and Ad Skepticism on Consumer Persuasion. Journal of Promotion Management, v. 22, n. 3, p. 403-424, 3 maio 2016.

ANATEL. ANATEL - Agência Nacional de Telecomunicações. Disponível em: <http://www. anatel.gov.br/dados/destaque-1>. Acesso em: 8 dez. 2017.

ARAUJO, T. C. C. F.; ARRAES, E. L. M. Necessidades e expectativas de atuação do psicólogo em cirurgia e procedimentos invasivos. Revista de Estudos de Psicologia, v. 18, n. 1, p. 64-73, 2001.

ARENS, W. F.; SCHAEFER, D. H.; WEIGOLD, M. F. Propaganda. Porto Alegre: Bookman, 2013.

AUSTIN, E. W.; CHEN, M. J.; GRUBE, J. W. How does alcohol advertising influence underage drinking? The role of desirability, identification and skepticism. Journal of Adolescent Health, v. 38, n. 4, p. 376-384, 2006.

AZEVEDO, C. E. F. et al. Por que Finanças ? Avaliando o interesse dos estudantes de graduação em Administração pela área de Finanças. RAM. Revista de Administração Mackenzie, v. 13, n. 6, p. 168-196, 2012.

BOUSH, D. M.; FRIESTAD, M.; ROSE, G. Adolescent skepticism toward TV advertising and knowledge of advertiser tactics. Journal of Consumer Research, v. 21, 1994.

BRAGA JUNIOR, S. S. et al. Effect of environmental concern and skepticism in the consumption green products in brazilian retail. Espácios, v. 37, n. 2, p. 13, 2016.

BYRNE, B. M. Structural Equation Modeling with AMOS: basic concepts, applications, and programming. 2. Ed. ed. New York: Routledge, 2010.

CHEN, F.-P.; LEU, J.-D. Product Involvement in the Link Between Skepticism Toward Advertising and Its Effects. Social Behavior and Personality: an international journal, v. 39, n. 2, p. 153-159, 1 mar. 2011.

CHIN, W. W. The Partial Least Squares approach to structural equation modeling. In: MARCOULIDES, G. A. (Ed.). . Modern Methods for Business Research. Mahwah, NJ: Lawrence Erlbaum Assoicates, 1998.

COSTA, F. J. DA et al. Valores pessoais e gestão socioambiental: um estudo com estudantes de Administração. RAM. Revista de Administração Mackenzie, v. 14, n. 3, p. 183-208, 2000.

CRESCITELLI, E. Crise de credibilidade da propaganda: considerações sobre seu impacto na eficácia da mensagem. Revista da Faculdade de Comunicação da FAAP - Facom, v. 12, 
n. 1, p. 51-59, 2004.

DALMORO, M.; VIEIRA, K. M. Dilemas na Construção de Escalas Tipo Likert: o Número de Itens e a Disposição Influenciam nos Resultados? Revista Gestão Organizacional, v. 6, n. 3, p. 161-174, 2013.

DIÓGENES, A. P.; SILVA, M. E. O estudo do ceticismo nas pesquisas de marketing verde: uma revisão de publicações brasileiras. Revista Gestão e Desenvolvimento, v. 14, n. 1, p. 70-83, 2017.

DUTRA, F. A história do telefone celular como distinção social no Brasil. Da elite empresarial ao consumo da classe popular. Revista Brasileira de História da Mídia, v. 5, n. 2, p. 102-116, 21 set. 2016.

EDEN, S.; BEAR, C.; WALKER, G. The sceptical consumer? Exploring views about food assurance. Food Policy, v. 33, n. 6, p. 624-630, 2008.

FERRAZ, S. B. et al. Produtos verdes: um estudo sobre atitude, intenção e comportamento de compra de universitários brasileiros. Revista de Administração da UFSM, v. 9, n. 4, p. 605-623, 2016.

FORNELL, C.; LARCKER, D. F. Evaluating structural equation models with unobservable variables and measurement error. Journal of Marketing Research, v. 18, n. 1, p. 39-50, 1981.

GRADVOHL, R. F.; LOPES, F. F. P.; COSTA, F. J. D. O Perfil do Bom Professor de Contabilidade: Uma Análise A Partir da Perspectiva de Alunos de Cursos de Graduação. Anais do $9^{\circ}$ Congresso USP de Controladoria e Contabilidade. Anais...São Paulo: 2009

HAIR, J. F. et al. Análise Multivariada de Dados. 6. ed. Porto Alegre, RS: Bookman Editora, 2009.

HAIR, J. F. et al. A primer on partial least squares structural equation modeling (PLS-SEM). Thousand Oaks: Sage, 2014.

HUERTAS, M. K. Z.; URDAN, A. As Dimensões da Atitude Frente à Propaganda de Medicamentos: uma Descrição no Brasil e Avaliação de Escala. Revista de Administração da UNIMEP, v. 7, n. 2, p. 138-158, 2009.

JACOMOSSI, R. R.; MORANO, R.; BARRICHELLO, A. Environmental behavior of graduate students: An international structural equation model applied to the brazilian context. Revista de Gestao Social e Ambiental, v. 8, n. 3, p. 106-117, 2014.

JARVENPAA, S. L.; MAJCHRZAK, A. Knowledge Collaboration Among Professionals Protecting National Security: Role of Transactive Memories in Ego-Centered Knowledge Networks. Organization Science, v. 19, n. 2, p. 260-276, 2008.

JU, I. The effects of advertising skepticism in consumer prescription drug advertising. International Journal of Pharmaceutical and Healthcare Marketing, v. 11, n. 4, p. 395-411, 6 nov. 2017.

KARJAluOTO, H. et al. Factors Affecting Consumer Choice of Mobile Phones: Two Studies from Finland. Journal of Euromarketing, v. 14, n. 3, p. 59-82, 11 abr. 2005.

KETOLA, P. Integrating usability with concurrent engineering in mobile phone develop- 
ment. Tampere: University of Tampere., 2002.

KIM, D.-Y.; KIM, S.-B.; KIM, K. J. Building corporate reputation, overcoming consumer skepticism, and establishing trust: choosing the right message types and social causes in the restaurant industry. Service Business, v. 13, n. 2, p. 363-388, 18 jun. 2019.

KOCK, N. Common method bias in PLS-SEM: A full collinearity assessment approach. International Journal of e-Collaboration, v. 11, n. 4, p. 1-10, 2015.

LE BORGNE, G.; SIRIEIX, L.; COSTA, S. Perceived probability of food waste: Influence on consumer attitudes towards and choice of sales promotions. Journal of Retailing and Consumer Services, v. 42, p. 11-21, 1 maio 2018.

LINDELL, M. K.; WHITNEY, D. J. Accounting for Common Method Variance in Cross-Selectional Research Designs. Journal of Applied Psychology, v. 86, n. 1, p. 114-121, 2001.

LOW, G. S.; MOHR, J. J. Advertising vs sales promotion: A brand management perspective. Journal of Product \& Brand Management, v. 9, n. 6, p. 389-414, 2000.

LUNARDO, R. Negative effects of ambient scents on consumers' skepticism about retailer's motive. Journal of Retailing and Consumer Services, v. 19, n. 2, p. 179-185, 2012.

MACARTHUR, D. Skepticism, self-knowledge, and responsibility. In: HETHERINGTON, S. (Ed.). . Aspects of Knowing: Epistemological Essays. 1st. ed. Amsterdan: Elsevier, 2006.

MATOS, C. A. DE; VEIGA, R. T. Os efeitos da publicidade negativa nas atitudes dos consumidores. Caderno de Pesquisas em Administração, São Paulo, v. 10, n. 2, p. 69-86, 2003.

MOHR, L. A.; EROGLU, D.; ELLEN, P. S. The Development and Testing of a Measure of Skepticism Toward Environmental Claims in Marketers' Communications. Journal of Consumer Affairs, v. 32, n. 1, p. 30-55, 1998.

MORAIS, F. R.; SOUZA, W. S. A Importância do Marketing na Percepção de Estudantes de Graduação e Profissionais da Área Contábil. Revista Organizações em Contexto, v. 11, n. 21, p. 73-100, 2015.

MOREL, K. P. N.; PRUYN, A. T. H. Consumer Skepticism Toward New Products. European Advances in Consumer Research, v. 6, p. 351-358, 2003.

MULTANI, G. S. et al. A Study on Advertising Credibility and Skepticism in Five Different Media Using the Persuasion Knowledge Model “. Gujarat, India: [s.n.].

OBERMILLER, C.; SPANGENBERG, E. R. Development of a Scale to Measure Consumer Skepticism Toward Advertising. Journal of Consumer Psychology, v. 7, n. 2, p. 159-186, 1998.

PACHECO, B. G.; RAHMAN, A. Effects of sales promotion type and promotion depth on consumer perceptions: the moderating role of retailer reputation. The International Review of Retail, Distribution and Consumer Research, v. 25, n. 1, p. 72-86, 20 jan. 2015.

PARRA, D.; AMATRIAIN, X. Walk the Talk: Analyzing the relation between implicit and explicit feedback for preference elicitation. Nineteenth International Conference on User Modeling, Adaption, and Personalization. Anais...Girona: 2011

PATEL, J. D.; GADHAVI, D. D.; SHUKLA, Y. S. Consumers' responses to cause related marketing: moderating influence of cause involvement and skepticism on attitude and purchase 
intention. International Review on Public and Nonprofit Marketing, v. 14, n. 1, p. 1-18, 27 mar. 2017.

PERRUPATO, L. C. As atitudes do consumidor em relação à propaganda. [s.l.] Centro Universitário Nove de Julho - UNINOVE, 2006.

RICHARDSON, H. A.; SIMMERING, M. J.; STURMAN, M. C. A Tale of Three Perspectives : Examining Post Hoc Statistical Techniques for Detection and Corrections of Common Method Variance. Organizational Methods, v. 12, n. 4, p. 200-762, 2009.

RIES, A.; RIES, L. A Queda da Propaganda: da mídia paga à mídia espontânea. Rio de Janeiro: Campus, 2002.

RINGLE, C. M.; DA SILVA, D.; BIDO, D. D. S. Modelagem de equações estruturais com utilização do SmartPLS. Revista Brasileira de Marketing - Remark, v. 13, n. 02, p. 56-73, 2014.

SACHER, H.; LOUDON, G. Uncovering the new wireless interaction paradigm. ACM Interactions Magazine, v. 9, n. 1, p. 17-23, 2002.

SCHINDLER, R. M.; MORRIN, M.; BECHWATI, N. N. Shipping charges and shipping-charge skepticism: Implications for direct marketers' pricing formats. Journal of Interactive Marketing, v. 19, n. 1, p. 41-53, 2005.

SHER, P. J.; LEE, S.-H. Consumer skepticism and online reviews: An Elaboration Likelihood Model perspective. Social Behavior and Personality: an international journal, v. 37, n. 1 , p. 137-143, 2009.

SILVA, S. R. DA. "EU NÃO VIVO SEM CELULAR": Sociabilidade, Consumo, Corporalidade e Novas Práticas nas Culturas Urbanas. Intexto, v. 2, n. 17, p. 1-17, 2007.

SKARMEAS, D.; LEONIDOU, C. N. When consumers doubt, Watch out! The role of CSR skepticism. Journal of Business Research, v. 66, n. 10, p. 1831-1838, 2013.

TAN, S.; TAN, K. Antecedents and Consequences of Skepticism toward Health Claims: An Empirical Investigation of Singaporean Consumers. Journal of Marketing Communications, v. 13, n. 1, p. 59-82, 2007.

VINZI, V. E. et al. (EDS.). Handbook of Partial Least Squares. Berlin: Springer, 2010.

WILSON, T. D.; LINDSEY, S.; SCHOOLER, T. Y. A model of dual attitudes. Psychological Review, v. 107, n. 1, p. 101-126, 2000.

WONG, K. K.-K. Partial Least Squares Structural Equation Modeling (PLS-SEM) Techniques Using SmartPLS. Marketing Bulletin, v. 24, n. 1, p. 1-32, 2013.

XUE, J.; HUANG, L.; LIANG, X. How should online stores implement coping strategies to fight against deceptive promotions? Electronic Commerce Research and Applications, v. 36, p. 100860, 1 jul. 2019. 


\section{APÊNDICE 1}

\begin{tabular}{|c|c|c|}
\hline \multirow{2}{*}{ Construto } & \multicolumn{2}{|r|}{ Indicador } \\
\hline & Código & Conteúdo \\
\hline \multirow{4}{*}{ 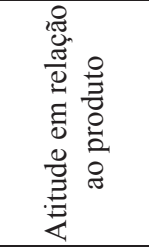 } & AtiProd2-2 & $\begin{array}{l}\text { A opinião de amigos é um fator importante na tomada de } \\
\text { decisão sobre a aquisição do novo celular. }\end{array}$ \\
\hline & AtiProd3-3 & $\begin{array}{l}\text { O preço é um fator determinante para aquisição de } \\
\text { determinado aparelho. }(\mathrm{R})\end{array}$ \\
\hline & AtiProd5-5 & Meu principal uso do celular é para ligações. (R) \\
\hline & AtiProd6-6 & O uso de internet é o meu principal uso do celular. \\
\hline \multirow{5}{*}{ 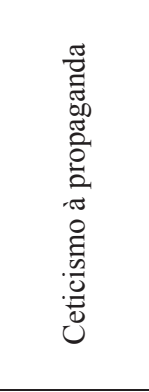 } & CetProp2-11 & $\begin{array}{l}\text { As propagandas não apresentam todas as informações } \\
\text { necessárias para o consumidor realizar a compra. }\end{array}$ \\
\hline & CetProp3-12 & $\begin{array}{l}\text { As propagandas não apresentam as verdadeiras } \\
\text { funcionalidades dos produtos ou serviços. }\end{array}$ \\
\hline & CetProp4-14 & $\begin{array}{l}\text { Eu acredito que a propaganda manipula a informação } \\
\text { apresentada para melhorar as vendas. }\end{array}$ \\
\hline & CetProp5-18 & $\begin{array}{l}\text { Geralmente, eu não vejo "propagandas" por não acreditar } \\
\text { nelas. }\end{array}$ \\
\hline & CetProp6-19 & $\begin{array}{l}\text { As empresas nunca cumprem as promessas feitas nas } \\
\text { propagandas. }\end{array}$ \\
\hline \multirow{3}{*}{ 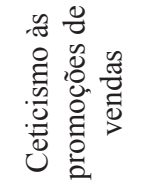 } & CetProm1-13 & $\begin{array}{l}\text { Promoções são feitas para estimular a compra, mesmo quando } \\
\text { o consumidor não precisa do produto ou serviço ofertado. }\end{array}$ \\
\hline & CetProm3-16 & Promoções só servem para enganar os clientes. \\
\hline & CetProm4-17 & As empresas enganam os clientes através de promoções. \\
\hline
\end{tabular}

Recebido em: 3-1-2018

Aprovado em: 4-7-2019

Avaliado pelo sistema double blind review.

Editor: Coordenação do PPGA/UMESP

Disponível em http://mjs.metodista.br/index.php/roc 